\title{
Surface enhanced Raman scattering optimization of gold nanocylinder arrays: Influence of the localized surface plasmon resonance and excitation wavelength
}

\author{
N. Guillot, ${ }^{1}$ H. Shen, ${ }^{2}$ B. Frémaux, ${ }^{1}$ O. Péron, ${ }^{3}$ E. Rinnert, ${ }^{3}$ T. Toury, ${ }^{2}$ and \\ M. Lamy de la Chapelle 1 ,a) \\ ${ }^{1}$ Laboratoire CSPBAT (FRE 3043), UFR SMBH, équipe LBPS, Université Paris XIII, 74 rue Marcel \\ Cachin, 93017 Bobigny, France \\ ${ }^{2}$ Institut Charles Delaunay-LNIO_UMR CNRS 6279, Université de technologie de Troyes, 12 rue Marie \\ Curie, 10010 Troyes, France \\ ${ }^{3}$ Département Recherches et Développements Technologiques, Service Interfaces et Capteurs, IFREMER, \\ BP70, 29280 Plouzané, France
}

(Received 7 April 2010; accepted 15 June 2010; published online 16 July 2010)

\begin{abstract}
We here emphasize that the surface enhanced Raman scattering (SERS) intensity has to be optimized by choosing the appropriate gold nanoparticles size for two excitation wavelengths; 632.8 and $785 \mathrm{~nm}$. We discuss the role of the position and of the order of the localized surface plasmon resonance (LSPR) in such optimization for both wavelengths. At $632.8 \mathrm{~nm}$, the best SERS intensity is reached for a LSPR located between the excitation and Raman wavelengths whereas at $785 \mathrm{~nm}$, the LSPR should be placed outside this range. The third order of LSPR is shown to have no influence on the SERS intensity. (C) 2010 American Institute of Physics. [doi:10.1063/1.3462068]
\end{abstract}

The size-dependant optical properties of noble metal nanoparticles have been intensively studied in the past 20 years and exploited in many applications and notably for bioor chemical sensors. ${ }^{1}$ The main parameter of these properties is the localized surface plasmon resonance (LSPR) known to generate a strong local enhancement of the electromagnetic field at the vicinity of metallic nanoparticles. ${ }^{2}$ This phenomenon is the basis of the surface enhanced Raman scattering (SERS) ${ }^{2,3}$ The Raman intensity, intrinsically weak, of a molecule adsorbed at a metallic nanoparticles surface benefits from this strong local field enhancement to provide the so called electromagnetic effect. The final SERS intensity can then be expressed as following: $I_{\text {SERS }}=f^{2}\left(\lambda_{0}\right) \times f^{2}\left(\lambda_{R}\right) \times|E|^{2}$ where $f\left(\lambda_{0}\right)$ and $f\left(\lambda_{R}\right)$ are, respectively, the enhancement factors at the excitation and Raman wavelengths ${ }^{4-6}$ and $E$ is the electromagnetic field. SERS effect can be obtained with various kinds of metallic nanostructures. For example, we have worked on SERS effect obtained by deposition of gold colloidal solution. ${ }^{7}$ But this chemical way of SERS substrate synthesis presents two major drawbacks; first, nanoparticle structures and SERS response are not reproducible and second, the associated LSPR is not easily tuned to the excitation wavelength. On the opposite, nanolithographic techniques are known to provide a very good control of the size and the shape of the nanoparticles deposited on the substrate. This allows a precise control of the $\mathrm{LSPR}^{8}$ and, thus, of the Raman enhancement. ${ }^{4,5,9-12}$

According to Refs. 5, 10, and 12 in the case of nanocylinder or nanotriangle arrays, the best Raman enhancement is reached for a LSPR position between the excitation and the Raman wavelengths whereas it is not always the case for other shapes like nanowires. ${ }^{9}$ Moreover, in this latter case, it has been demonstrated the strong influence of the higher order of LSPR on SERS. ${ }^{9,13}$ Thus, by using a large range of

\footnotetext{
a) Author to whom correspondence should be addressed. Electronic mail: marc.lamydelachapelle@univ-paris13.fr.
}

cylinder diameters, we have studied the SERS efficiency of nanocylinder arrays at following two excitation wavelengths: 632.8 and $785 \mathrm{~nm}$, to determine the influence of the position and of the order of the LSPR on the SERS intensity.

The gold nanocylinder arrays are fabricated on glass substrates by electron beam lithography and lift-off techniques (for more details, see Ref. 12). The nanocylinder diameter varies from 80 to $580 \mathrm{~nm}$ whereas their height is kept constant at $50 \mathrm{~nm}$. A layer of $\mathrm{Cr}$ of $3 \mathrm{~nm}$ is also used to improve adhesion of gold on glass. The gap between two nanocylinders is also kept constant around $200 \mathrm{~nm}$. Thus, the distance between particles is large enough to avoid any near field coupling and, therefore, no effect on the LSPR position or the SERS signal. The nanocylinder shape, size, and array parameters were checked by scanning electron microscope (SEM) (Fig. 1).

For SERS measurements, the substrates were immersed in a $10^{-3} \mathrm{M}$ solution of a probe molecule, the trans-1,2bis(4-pyridyl)ethylene (BPE), during $1 \mathrm{~h}$ and dried. Extinction and Raman spectra were recorded with a Labram JobinYvon micro-Raman spectrophotometer (for technical details, see Ref. 14).

As shown in Fig. 1, when the diameter of the nanocylinders increases, the Raman signal reaches clearly a maximum for a diameter of $130 \mathrm{~nm}$ for an excitation wavelength of $632.8 \mathrm{~nm}$ and is very high compared to the majority of the other diameters (around one order of magnitude). In addition, no other maximum can be clearly observed on this curve. This result, obtained on a large range of diameters, confirms that this kind of SERS-active substrate must be optimized by choosing the appropriate size. ${ }^{9,12}$

The role of the LSPR generated by the nanolithographied substrate has been clearly identified. Indeed, as it is well known, the position of the LSPR is redshifted for higher diameter and higher mode of resonance (third order in our case) is also observed for large nanocylinders (diameter higher than $300 \mathrm{~nm}$ ). In fact, for arrays of gold nanocylin- 


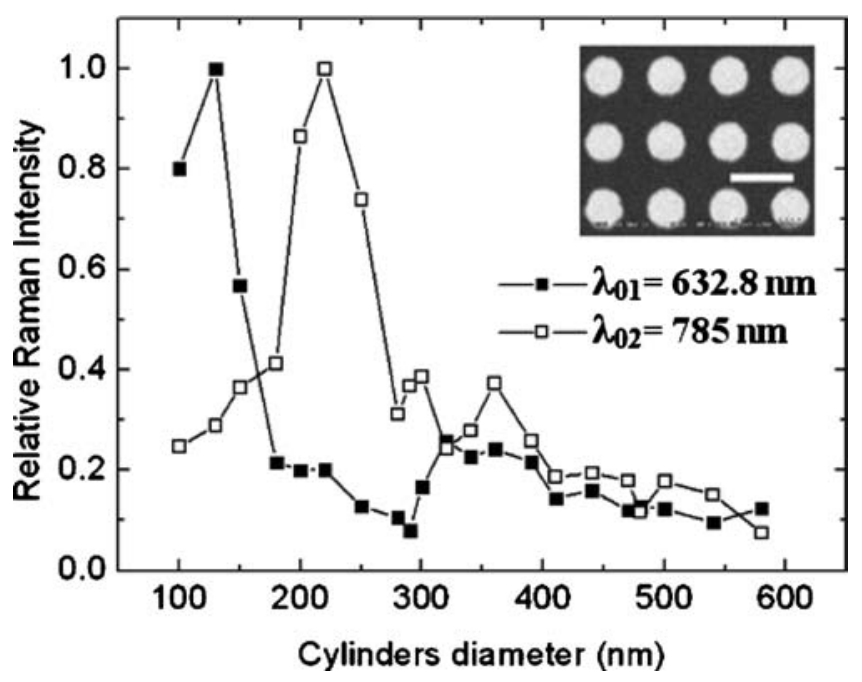

FIG. 1. Evolution of the relative Raman intensity (acquisition time: $10 \mathrm{~s}$ ) vs the nanocylinder diameters for two excitation wavelengths $\lambda_{01}=632.8 \mathrm{~nm}$ (black squares) and $\lambda_{02}=785 \mathrm{~nm}$ (white squares). For each curve, the SERS intensity has been normalized. The dotted lines are just used here as indicators of the trends. Inset: SEM image of gold nanocylinder array (diameter $=270 \mathrm{~nm}$, height $=50 \mathrm{~nm}$, and scale bar=500 nm).

ders, some have shown that the best Raman signal enhancement is obtained (Fig. 2) for the LSPR position $\lambda_{\text {LSPR }}$ located exactly between the excitation wavelength $\lambda_{0}$ and the Raman wavelength $\lambda_{R}$ (related to the band of interest of the probe molecule observed). ${ }^{5,12}$ More precisely, some have proposed that it should correspond to $\lambda_{\mathrm{LSPR}}=\left(\lambda_{\mathrm{L}}+\lambda_{\mathrm{R}}\right) / 2 .{ }^{5}$ Then, for excitation at $\lambda_{01}=632.8 \mathrm{~nm}$ and a Raman wavelength $\lambda_{\mathrm{R} 1}$ at $685 \mathrm{~nm}$ (BPE band at $1200 \mathrm{~cm}^{-1}$ ), the best LSPR position should be located at $659 \mathrm{~nm}$. For the first and third order, the corresponding nanocylinder diameters are, respectively, close to $130 \mathrm{~nm}$ and to $400 \mathrm{~nm}$ (Fig. 2). As shown in Fig. 3, this "rule" is effectively verified for the dipolar like LSPR mode whereas we can notice that the third order of resonance has few SERS activities. Indeed, looking at the Fig. 1, it is clear that there is no significant magnification of the Raman

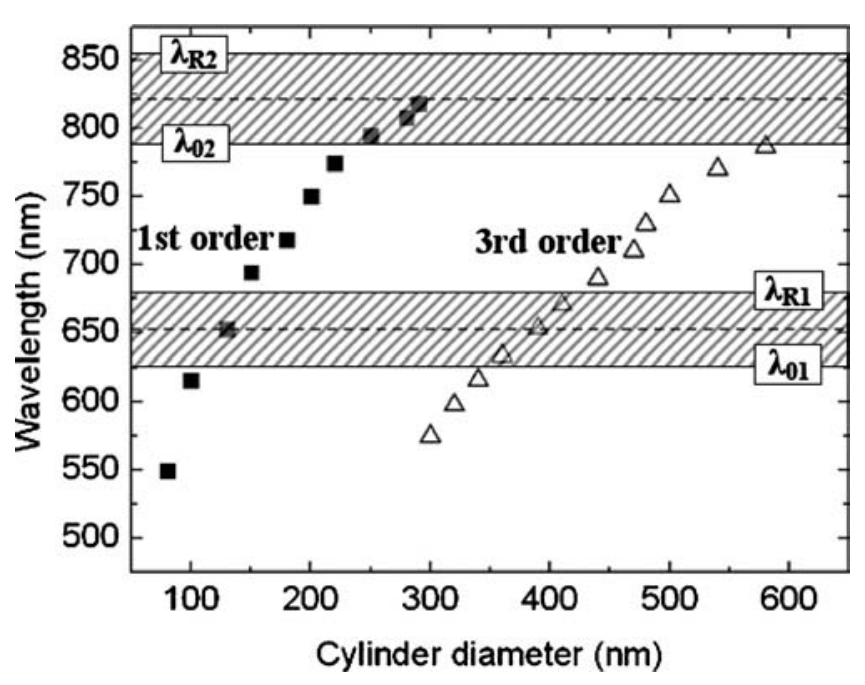

FIG. 2. Evolution of the LSPR position vs the cylinder diameter for the first order (black squares) and the third one (white triangles). $\lambda_{01}$ and $\lambda_{02}$ correspond, respectively, to the excitation wavelengths at 632.8 and $785 \mathrm{~nm} . \lambda_{\mathrm{R} 1}$ and $\lambda_{R 2}$ are, respectively, the Raman wavelengths of the BPE band at $1200 \mathrm{~cm}^{-1}$ when excited at $\lambda_{01}$ and $\lambda_{02}$. The dotted lines show the average position between $\lambda_{0}$ and $\lambda_{\mathrm{R}}$ for both excitation wavelengths.
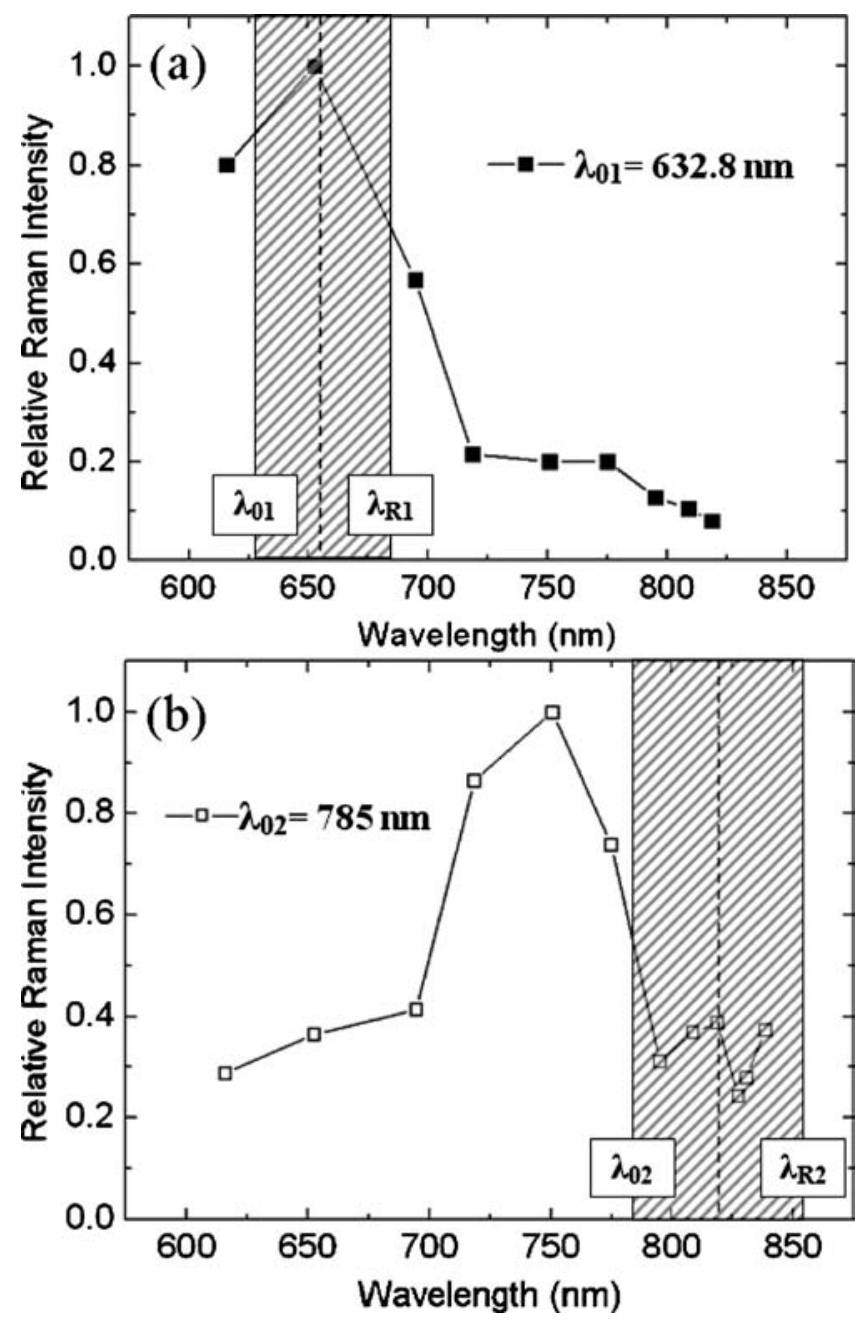

FIG. 3. Relative Raman Intensity vs the LSPR positions for the two excitation wavelengths $\lambda_{01}=632.8 \mathrm{~nm}$ (a) and $\lambda_{02}=785 \mathrm{~nm}$ (b) and reminder of the positions of the excitation and Raman wavelengths for each cases.

signal for diameters around $400 \mathrm{~nm}$. It means that for this shape, the higher orders of resonance have few effects on the Raman signal. This behavior is opposite from the one observed with elongated nanoparticles like nanowires where the higher orders have strong SERS activity which can even be higher than the dipolar mode. ${ }^{9}$

We have also investigated the SERS efficiency of the nanocylinders with another excitation wavelength $\lambda_{02}$ $=785 \mathrm{~nm}$. Now, if we apply the rule previously observed for $632.8 \mathrm{~nm}$, the best Raman enhancement should be obtained for a $\lambda_{\mathrm{LSPR}}$ close to $820 \mathrm{~nm}$ since the Raman wavelength $\lambda_{\mathrm{R} 2}$ is located at $859 \mathrm{~nm}$. For the first order, the corresponding cylinder diameter is close to $300 \mathrm{~nm}$. Referring to the Fig. 1, we clearly see a strong peak a SERS intensity maximum for a diameter of $220 \mathrm{~nm}$ and not $300 \mathrm{~nm}$ as expected. Thus, as shown on Fig. 3(b), the best Raman signal is obtained for a $\lambda_{\mathrm{LSPR}}$ close to $750 \mathrm{~nm}$ largely outside the $\lambda_{02}-\lambda_{\mathrm{R} 2}$ range and the optimal LSPR is strongly shifted compared the expected wavelength. This observation gives evidence that the "rule" indicating that the $\lambda_{\mathrm{LSPR}}$ should be located in the $\lambda_{0}-\lambda_{\mathrm{R}}$ range is not applicable on the whole visible range and strongly depends on the excitation wavelength used. We can assume that the link between the LSPR measured in far field (extinction spectroscopy) and the SERS signal considered as a near field process is not straightforward. Indeed, as it has 
yet been demonstrated by Grimault et al., ${ }^{15}$ the field enhancement in the near field and at the vicinity of the nanoparticle surface is not directly related to the plasmon intensity. There is actually some shift between the plasmon resonance maximum and the maximum field enhancement reaches at the particle surface. Thus, it is of real importance to consider this fact for the SERS optimization, especially in the case of SERS sensor development.

In this work, we demonstrated the optimization abilities of the SERS intensity provided by arrays of gold nanocylinders. In fact, for nanocylinders with $130 \mathrm{~nm}$ diameters, we obtain the best SERS intensity with a corresponding LSPR position between the excitation $(632.8 \mathrm{~nm})$ and Raman wavelength. However, with an excitation wavelength of 785 $\mathrm{nm}$, the best SERS intensity is obtained for a corresponding LSPR outside the area excitation-Raman wavelengths. Finally, the higher orders of the LSPR resonances have been shown to have a very low influence on the SERS intensity.

The authors want to acknowledge the French National Agency (ANR) Grant No. 07-P2IC-002 Discomar Project and the Conseil Régional de Champagne Ardenne for financial support.

${ }^{1}$ S. Xu, X. Ji, W. Xu, B. Zhao, X. Duo, Y. Bai, and Y. Ozaki, J. Biomed. Opt. 10, 031112 (2005); P. Douglas, R. J. Stokes, D. Graham, and W. E. Smith, Analyst (Cambridge, U.K.) 133, 791 (2008); R. J. Stokes, E. McBride, C. G. Wilson, J. M. Girkin, W. E. Smith, and D. Graham, Appl. Spectrosc. 62, 371 (2008); X. Qian, X.-H. Peng, D. Ansari, Q. Yin-Goen, G. Z. Chen, D. M. Shin, L. Yang, A. N. Young, M. D. Wang, and S. Nie, Nat. Biotechnol. 26, 83 (2008); K. E. Shafer-Peltier, C. L. Haynes, M. R. Glucksberg, and R. P. Van Duyne, J. Am. Chem. Soc. 125, 588 (2003); D. A. Stuart, J. M. Yuen, N. Shah, O. Lyandres, C. R. Yonzon, M. R. Glucksberg, J. T. Walsh, and R. P. Van Duyne, Anal. Chem. 78, 7211 (2006); X. Zhang, N. C. Shah, and R. P. Van Duyne, Vib. Spectrosc. 42, 2 (2006); G. Das, F. Mecarini, F. Gentille, F. De Angelis, M. Kumar, P. Candeloro, C. Liberale, G. Cuda, and E. Di Fabrizio, Biosens. Bioelectron. 24, 1693 (2009); G. Barbillon, J.-L. Bijeon, J. Plain, M. Lamy de la Chapelle, P.-M. Adam, and P. Royer, Surf. Sci. 601, 5057 (2007).

${ }^{2}$ H. Raether, Surface Plasmons on Smooth and Rough Surfaces and on
Gratings, Springer Tracts in Modern Physics Vol. 111 (Springer, Berlin, 1988); A. W. Wokaun, in Solid State Physics, edited by H. Ehrenreich, F. Seitz, and D. Turnbull (Academic, New York, 1984), Vol. 38, p. 223.

${ }^{3}$ D. L. Jeanmaire and R. P. V. Duyne, J. Electroanal. Chem. 84, 1 (1977).

${ }^{4}$ N. Félidj, J. Aubard, G. Lévi, J. R. Krenn, M. Salerno, G. Schider, B. Lamprecht, A. Leitner, and F. R. Aussenegg, Phys. Rev. B 65, 075419 (2002).

${ }^{5}$ N. Félidj, J. Aubard, G. Lévi, J. R. Krenn, A. Hohenau, G. Schider, A. Leitner, and F. R. Aussenegg, Appl. Phys. Lett. 82, 3095 (2003).

${ }^{6}$ E. C. Le Ru, P. G. Etchegoin, J. Grand, N. Félidj, J. Aubard, G. Lévi, A. Hohenau, and J. R. Krenn, Curr. Appl. Phys. 8, 467 (2008).

${ }^{7}$ O. Péron, E. Rinnert, M. Lehaitre, F. Colas, and C. Compère, Proc. SPIE 7312, 73120D1 (2009); O. Péron, E. Rinnert, M. Lehaitre, P. Crassous, and C. Compère, Talanta 79, 199 (2009).

${ }^{8}$ K. Ueno, V. Mizeikis, S. Juodkazis, K. Sasaki, and H. Misawa, Opt. Lett. 30, 2158 (2005); J. R. Krenn, G. Schider, W. Rechberger, B. Lamprecht, A. Leitner, F. R. Aussenegg, and J. C. Weeber, Appl. Phys. Lett. 77, 3379 (2000); J. Grand, P.-M. Adam, A.-S. Grimault, A. Vial, M. Lamy de la Chapelle, J.-L. Bijeon, S. Kostcheev, and P. Royer, Plasmonics 1, 135 (2006).

${ }^{9}$ L. Billot, M. Lamy de la Chapelle, A.-S. Grimault, A. Vial, D. Barchiesi, J.-L. Bijeon, P.-M. Adam, and P. Royer, Chem. Phys. Lett. 422, 303 (2006).

${ }^{10}$ C. L. Haynes and R. P. Van Duyne, J. Phys. Chem. B 107, 7426 (2003).

${ }^{11}$ A. D. McFarland, M. A. Young, J. A. Dieringer, and R. P. Van Duyne, J. Phys. Chem. B 109, 11279 (2005).

${ }^{12}$ J. Grand, S. Kostcheev, J.-L. Bijeon, M. Lamy de la Chapelle, P.-M. Adam, A. Rumyantseva, G. Lérondel, and P. Royer, Synth. Met. 139, 621 (2003); J. Grand, M. Lamy de la Chapelle, J.-L. Bijeon, P.-M. Adam, A. Vial, and P. Royer, Phys. Rev. B 72, 033407 (2005).

${ }^{13}$ G. Laurent, N. Félidj, J. Aubard, G. Lévi, J. R. Krenn, A. Hohenau, G. Schider, A. Leitner, and F. R. Aussenegg, Phys. Rev. B 71, 045430 (2005); J. Chem. Phys. 122, 011102 (2005).

${ }^{14}$ The extinction spectra are recorded in transmission configuration with a $10 \times$ objective $(\mathrm{NA}=0.25)$ by removing the edge filters and on an area of $100 \times 100 \mu \mathrm{m}^{2}$ selected by the confocal hole. The sample is illuminated in normal incidence with collimated white light. For Raman spectroscopy, we used a $100 \times$ magnification objective $(\mathrm{NA}=0.90)$ in back scattering geometry. Raman measurements are carried out with the $632.8 \mathrm{~nm}$ line of an $\mathrm{He}-\mathrm{Ne}$ laser and also the $785 \mathrm{~nm}$ one of a laser diode. The intensity of the signal is estimated by calculating the area of the Lorentzian fitted BPE band located at $1200 \mathrm{~cm}^{-1}$.

${ }^{15}$ A.-S. Grimault, A. Vial, and M. Lamy de la Chapelle, Appl. Phys. B: Lasers Opt. 84, 111 (2006). 